JUURNAL

of Health Inequalities

\title{
Letter to the Editors concerning the paper "The burden of avoidable disease from air pollution: implications for prevention"
}

\author{
Cezary Wojtyła \\ International Prevention Research Institute - Collaborating Centre, Calisia University, Kalisz, Poland \\ Department of Oncologic Gynecology and Obstetrics, Centre of Postgraduate Medical Education, Warsaw, Poland
}

ADDRESS FOR CORRESPONDENCE: Cezary Wojtyła, International Prevention Research Institute - Collaborating Centre, Calisia University, 16 Kaszubska St., 62-800 Kalisz, Poland, e-mail: czwo@op.pl

In their recent paper entitled "The burden of avoidable disease from air pollution: implications for prevention", Jonathan Samet and Meghan Buran discuss one of the most important, current problems of public health [1]. Air pollution is nowadays the greatest threat to the health of the population around the world. It is not without reason that the World Health Organization (WHO) defined air pollution as the single greatest environmental risk to health [2], at the same time specifying the problem as the "new tobacco" [3]. As the authors of the paper point out, both smoking and ambient air pollution make major contributions to disease burden. There are many similarities between air pollution and smoking, in terms of population exposure, the possibility of reducing adverse health effects through adequate control of its intake and emission, and the foreseeable resistance to legislative solutions from groups to which these branches of the economy bring income. Despite the benefits of introducing appropriate regulations of air pollution and tobacco smoking control, the costs required to develop these are incomparable. However, we should always remember the consequences of not introducing regulations, especially in the case of countries such as Poland, where high levels of PM2.5 are still observed. According to the WHO Ambient Air Pollution Database, over 30 of the 50 most polluted cities in Europe are located in Poland [4]. This situation contributes annually to about 23,500 premature deaths [1]. The scale is likely much larger. It should be remembered that the negative impact of air pollution on pregnancy and the development of a child in the following years of their life possibly lead to premature death in the future.
The developing fetus is extremely sensitive to the harmful effects of air pollution and its compounds inhaled by a pregnant woman. These compounds are transferred through the pulmonary alveoli to the maternal circulation, reaching in effect the placenta and the fetal circulation [5]. The immature immunological system and liver of the fetus make the metabolism of these compounds and their elimination difficult. Exposure of a pregnant woman to compounds contained in polluted air may result in intrauterine growth restriction, preterm birth, low birthweight, development of congenital abnormalities, and unfavorable course of pregnancy or delivery $[6,7]$. The fetal DNA repair mechanisms are also immature, which, with the simultaneous intense proliferation of cells, leads to changes in the genetic material and epigenetic changes that multiply during subsequent cell divisions, increasing the risk of chronic diseases and cancer in postnatal life, and may lead to premature death $[7,8]$.

Today's air pollution could take its toll on human health for decades to come. Thus, the earlier appropriate control policies are taken to reduce it, the healthier society will be, not only today but also in the future.

\section{DISCLOSURE}

The author reports no conflict of interest.

\section{References}

1. Samet J, Buran M. The burden of avoidable disease from air pollution: implications for prevention. J Health Inequal 2020; $6(1): 2-6$.

2. Ten threats to global health in 2019. Available from: https:// www.who.int/news-room/spotlight/ten-threats-to-globalhealth-in-2019 (accessed: 28 November 2020). 
3. The Guardian. Air pollution is the 'new tobacco', warns WHO head. Available from: https://www.theguardian.com/environment/2018/oct/27/air-pollution-is-the-new-tobacco-warnswho-head (accessed: 28 November 2020).

4. Parascandola M. Ambient air pollution and lung cancer in Poland: research findings and gaps. J Health Inequal 2018; 4 (1): 3-8.

5. Jedrychowski WA, Majewska R, Spengler JD, et al. Prenatal exposure to fine particles and polycyclic aromatic hydrocarbons and birth outcomes: a two-pollutant approach. Int Arch Occup Environ Health 2017; 90 (3): 255-264.

6. Wojtyla C, Zielinska K, Wojtyla-Buciora P, Panek G. Prenatal fine particulate matter (PM2.5) exposure and pregnancy outcomes - analysis of term pregnancies in Poland. Int J Environ Res Public Health 2020; 17 (16): 5820.

7. Jirtle RL, Skinner MK. Environmental epigenomics and disease susceptibility. Nat Rev Genet 2007; 8 (4): 253-262.

8. Perera F. Molecular epidemiology, prenatal exposure and prevention of cancer. Environ Health 2011; 10 (Suppl 1): 55. 